\title{
HBIM IMPLEMENTATION FOR AN OTTOMAN MOSQUE. CASE OF STUDY: SULTAN MEHMET FATIH II MOSQUE IN KOSOVO
}

\author{
Francesco Di Stefano ${ }^{1 *}$, Eva Savina Malinverni ${ }^{1}$, Roberto Pierdicca ${ }^{1}$, Gabriele Fangi ${ }^{1}$, Shkurte Ejupi ${ }^{1}$ \\ ${ }^{1}$ Università Politecnica delle Marche, Dipartimento di Ingegneria Civile, Edile e dell’Architettura, 60100 Ancona, Italy \\ \{f.distefano@pm.univpm.it; (e.s.malinverni, r.pierdicca)@univpm.it; gabrielefangi@gmail.com; shkurtejupi@gmail.com\}
}

\section{Commission II, WG II/8}

KEY WORDS: cultural heritage, mosque, spherical photogrammetry, 3D modelling, HBIM, semantic data management

\begin{abstract}
:
National Strategy For Cultural Heritage 2017-2027 is a Kosovo Government document that aims the enhancement of the system for the protection and preservation of Kosovan cultural heritage. Among the listed goals, one can find the promotion of an integrated data management approach towards cooperation platforms that involve advanced technologies and information systems applied to cultural heritage. In a country with a low technological progress, as Kosovo is, an innovative information management system like HBIM is a huge challenge. This research contributes in opening the debate about the use of HBIM even for historical architecture, illustrating a methodology of information management promoting the conservation and the valorization of a Kosovan ottoman mosque. The workflow pipeline started with the close range photogrammetric survey, obtaining first spherical panoramas and then the wire-frame processed in a 3D modelling environment, suitable to implement the HBIM project. Basing on the accuracy of the data acquisition, the availability of information about the building and the related level of knowledge, we proposed a semantic representation of the complex structure integrating in an HBIM collecting in an "ad hoc" database the geometrical building components, enriched with attributes as images, materials, decay, interventions, etc., linked to each features. Our approach is an example of how efficient semantic classification can be repeated for the analysis and the documentation of other similar ottoman mosque, simplifying the management of construction by a sort of unique and searchable archive. The advantage of the interoperability concept allows the data sharing is now stressed by HBIM.
\end{abstract}

\section{INTRODUCTION}

According to Historical England and the Department for Communities and Local Government of United Kingdom the definition of Heritage assets is: "A building, monument, site, place, area or landscape identified as having a degree of significance meriting consideration in planning decisions, because of its heritage interest." (Department for Communities and Local Government of United Kingdom, 2012). Historic buildings and sites should be preserved as cultural legacy and common heritage (Gazzola et al. 1964). The Charter of Krakow is the most recent document defining the principles for conservation and restoration of built heritage. (De Naeyer et al. 2000; Petzet, 2004). There are categories among the existing buildings and sites depending on its cultural values, antiquity or artistic importance. They are categorised depending on the country or state; generally, they include common recent existing buildings, catalogued buildings with protected areas and heritage buildings that are clearly protected (Eppich, 2007). Considering the definition of the Outstanding Universal Value (ICOMOS Convention, 1972), all the information available about a historical building is useful to allow a widespread reconstruction, interpretation, conservation and dissemination for future generations. Tangible cultural heritage, particularly immovable assets (monuments, archaeological sites, and so on), is the main subject of application in the new approaches. A structured digital $3 \mathrm{D}$ model as part of the architectural heritage improvement process is an urgent need, nowadays. Moreover, the digital 3D model must be converted into a crucial reference frame for the understanding and monitoring of documentation, thus creating a data source (graphics and semantics) that is suitable for assisting in conservation, restoration, and reconstruction projects (Penttilä et al., 2007)
Over the last decades, innovative 3D digitisations and geomatics technologies has entered the field of cultural heritage, mainly in order to meet the needs of documentation, management and protection. The aim is to ensure that the information regarding the significant historical characteristics (shape, appearance) of a cultural heritage entity will be reserved in case of natural or other damages. (Gomes et al., 2014).

National Strategy For Cultural Heritage 2017-2027 (Ministry of Culture, Youth and Sport of Kosovo, 2016) is a strategic document drafted by Kosovo Government with the aims to enhance a system for the protection and documentation of cultural heritage in Kosovo. The strategy is structured on several orientation actions, one includes the inventorying and digitization system of cultural heritage. Other goals are the promotion of an integrated data management approach towards cooperation platforms that involve advanced technologies and information systems applied to cultural heritage.

Many international polices, as the Horizon 2020-European Commission, architectural regulations (Antonopoulou et al. 2017) and different international conservation councils (Maxwell, 2016) highlight the need for collaborative systems which enables better information sharing in heritage building projects.

In a country with a low technological progress, as Kosovo is, an innovative information management system like HBIM implementation is a huge challenge. This reasearch contributes in opening the debate about the use of HBIM even for historical architecture illustrating a methodology of information management promoting the conservation and the valorization of Kosovan heritage.

This paper is structured as follows: after a first review of up to the date literature about the HBIM project for existing building (section 2), the adopted methodology will be outlined (section 3)

\footnotetext{
* Corresponding author
} 
illustrating the case of study, then the workflow pipeline from the data acquisition and processing to the HBIM implementation is showed finally considerations and results will be discussed in section 4 .

\section{HBIM FOR CULTURAL HERITAGE}

In recent years there has been an increasing experimentation of the BIM approach in the field of Cultural Heritage in order to assess its adequacy for documentation, restoration and management of historical heritage (Brumana et al, 2017; Bruno et al, 2018; Della Torre et al, 2019).

Photogrammetric techniques are particularly relevant for accelerating spatial data collection from existing buildings. (Gómez-García-Bermejo, 2013). Moreover, colour and material information can also be integrated or mapped by using digital reflex camera.

The processed data can be a starting point to give a product suitable for Building Information Modelling (BIM) platforms, adopted in recent years as a new paradigm for documentation and data management of existing assets, especially of the built historical monuments (Akbarnezhad et al, 2014).

BIM has been originally designed to support new buildings. This could make BIM adoption to heritage buildings challenging due to the specific characteristics of historic buildings (Barazzetti et al. 2015). For example, they have an extended time of use that usually alters some of their features: repurposed structures, reused materials and shape variations. Historic buildings usually include different architectural typologies, several historicconstructive phases and sometimes pathologies such as cracks or humidity (Green et al. 2016). Heritage stakeholders have different needs than those of regular Architecture, Engineering and Construction (AEC) professionals and these needs to take into account in a precious and useful manner (Megahed, 2015).

The first use of BIM applied to existing buildings is represented by the works of Arayici (2008) which attempts a first 3D modelling with integration of intelligent data.

In the same years the experiments of Murphy et al. (2009; 2013) to the. develop the Historic Building Information Modeling (HBIM) by creating libraries of parametric objects constructed from historical data and a system for mapping the parametric object. Murphy has defined HBIM as a new system of modelling historic structures creating full 2D and 3D models, which include detail behind the surface of the objects concerning its methods of construction and material makeup (Murphy et al. 2009). Recently, HBIM was also named Heritage Building Information Modelling, a broader term that includes historical data, conservation policies and significance values (Spanish Ministry of Education, Culture and Sports, 2004). Heritage BIM includes highly protected buildings that usually requires broader intervention projects and a careful life cycle management. Dore and Murphy (2017) proposed these HBIM elements: heritage documentation standards, data collection techniques, 3D modelling concepts, as-built BIM and procedural modelling. In the interesting work of Volk et al. (2014), the limits and the poor application of BIM on existing buildings are discussed through a critical analysis of numerous contributions in the literature.

Some of the issues expressed in the contributions are still current: difficulties in the modelling of non-standard forms, lack of automation in the conversion of data acquired from digital surveys into semantic objects, methods for entering information and documents. Even today, in the practice of the restoration project, BIM is still not widespread and often used as advanced CAD, neglecting its essence: information and its sharing. (Coli et al. 2019)
The development of an "as-built" BIM requires the data acquisition of the current state of the relevant structure (Macher et al., 2017), the geometrical modelling of the objects, the attribution of categories and material properties to the objects and the creation of relations between them (Hichri et al., 2013).

It is important to note that the libraries and tools of the BIM platforms focus on the design and construction of new buildings with simple, regular, and standardized objects (Bryde et al., 2013). For this reason, the virtual and detailed reconstruction of cultural-historical heritage has revealed some limitations of BIM platforms, such as the unavailability of historical parametric object libraries and the lack of tools for managing complex, irregular shapes that are obtained from the photogrammetric survey.

Historic buildings have different characteristics compared to new buildings. Each historic building is different from the other and has characteristics and singularities that make it a unicum.

The difference between common existing buildings and heritage ones is that heritage projects involve architectural, historic and archaeological documentation, so it involves the technical reproduction of a context, as well as an intellectual effort to describe the socio-cultural heritage setting (De Naeyer et al. 2000). The lifecycle of an historic building is cyclical for the periodic and recurring activities for its maintenance and restoration but also for managing several multi-temporal information. In addition, the whole history of the building must be considered and added to the information about the actual state (Bruno, 2018).

Basing on these main considerations, it's clear that HBIM implementation cannot follow a standard approach, but it needs to understand the Level of Detail (LoD) that can be based on acquired information and adopting a semantic description, essential for the representation of the artefact where data and entities are linked in a relational system. HBIM can be defined as a useful information system to enrich the knowledge about an existing building and it allows to manage heterogeneous data e.g. geometric, historical, thematic, etc. trying to put in order and combine them to enhance the heritage documentation. In addition, in field of restoration, a HBIM system represents an efficient tool for protection and conservation monitoring in order to prevent damage situations. (Malinverni et al.,2019)

\section{METHODOLOGY}

The aim of this work is to experiment the application of HBIM approach for the analysis of the monument, for its documentation, conservation and restoration purposes. In this direction the methodological pipeline (Fig. 1) that can be summarized following these steps:

- general overview;

- geometrical and architectural survey and data processing;

- individuation of the Level of Detail and semantic segmentation of the building structures, identification and classification system;

- data enrichment in terms of informative contents.

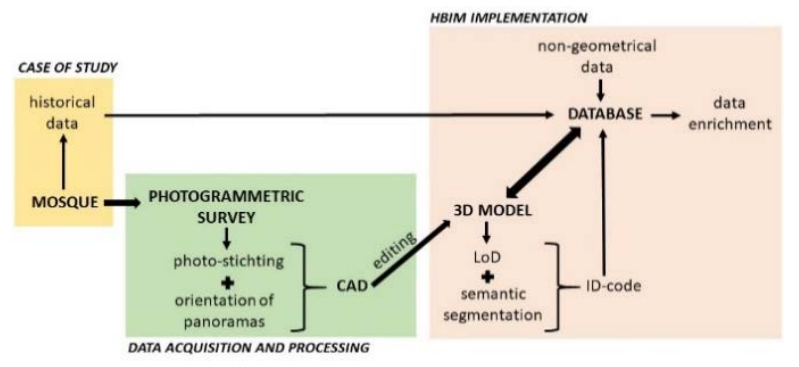

Figure 1 . The methodology workflow 


\subsection{Case of study}

This magnificent mosque (Fig. 2) was built by Sultan Mehmet II al-Fatih ("The Conqueror") in 1460-1461A.D., eight years after the fall of Constantinople and nine years before his mosque in Istanbul. It is located in the center of the historic city of Prishtina (Kosovo) beside the clock tower and represents its landmark. The mosque consists of two parts:

1- The porch $(5.9 \times 17.7 \mathrm{~m})$ consists of three compartments covered by small domes with pendentives in the corners. The domes rest on circular arches carried by stone pillars on the street side. The domes are covered with lead sheets.

2- The praying hall has a square plan of $13.98 \times 14.04 \mathrm{~m}$ from inside and $17.7 \times 17.6 \mathrm{~m}$ from outside with a wall thickness of about $1.35 \mathrm{~m}$

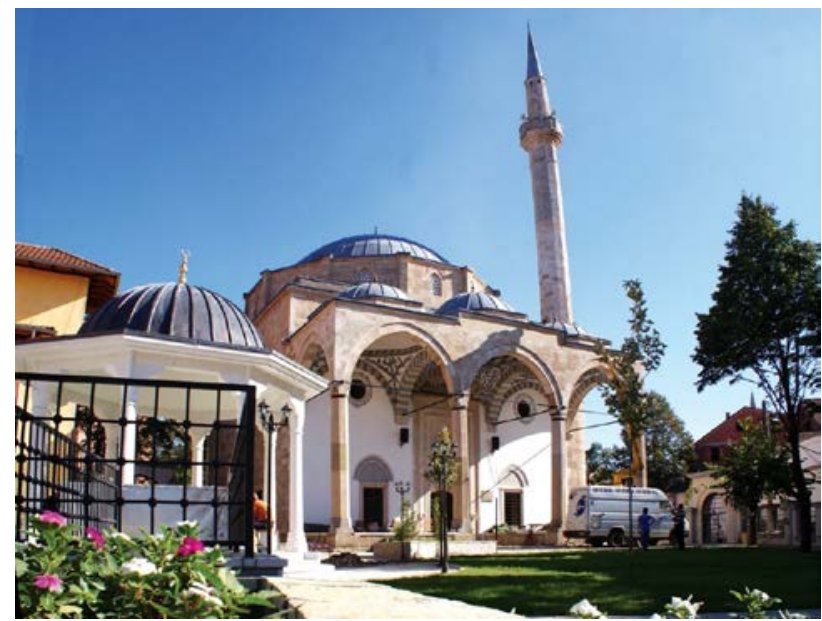

Figure 2. Sulltan Mehmet Fatih II Mosque, Prishtina (Kosovo)

On the right side of the entrance door, in the wall thickness, there is a one-flight stair leading to the wooden mezzanine (mahfil). In the Qibla wall and in its axis is the mihrab, as deep recessed niche with stalactites hood. To the left of the mihrab, in the building corner, stands the stool for spiritual sermons. On the left of the mihrab stands the minbar for the Friday speech.

The minaret is detached to the right side of the mosque in the northwest corner. Its entrance is located in minaret stool. It consists of a high stool ended with stalactite row, a conical transition zone, a high cylindrical storey ended with a balcony, a short cylindrical storey crowned by the typical ottoman cone covered by lead sheets. The stool is $2,70 \times 2,35 \mathrm{~m}$ and is hexagon in plain from outside, circular from inside and has spiral staircase. In the countryard of the mosque is also a great fountain built later than the mosque and enterely restored in 2010. Fourteen pipes springs from the marble fountain under a columned dome. It served for 'ablution', purification before prayer ritual. (Virmiça, 1999; Ramadan, 2007)

The documentation about the historical background of the mosque, due to an unstructured information system of Kosovan heritage, has been difficult to achieve and consequently it has been very hard to build the chronological profile of the architectural heritage.

\subsection{Data acquisition and processing}

Modern photogrammetry, together with laser scanning technology, have become very popular techniques in cultural heritage data acquisition. In architectural applications of these methods for historic buildings, attention is needed to the quality of the visualisation. When it is necessary to reconstruct the structure, materials, or form of a given heritage building or object, geometrical quality is key in the process of rebuilding or reconstruction. This paper proposes an assessment of geometrical content of 3D model for Heritage Building Information Modelling (HBIM) verifing also local reference measurements. The workflow starts with the data acquisition developing to the creation of the 3D model. The ground-based photogrammetric survey of interior and exterior environments of the mosque is carried by the reflex camera Canon EOS 1100D placed on the top of the tripod obtaining spherical panoramas made from different point positioning following a network schema (Fig. 3).

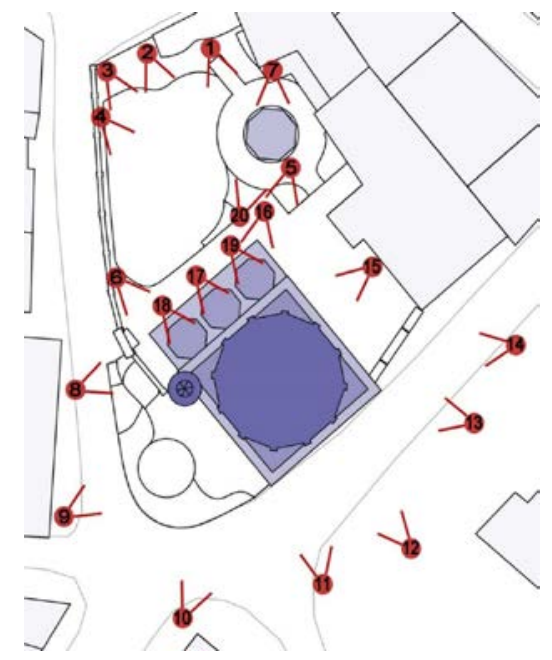

Figure 3. The schema of ground-based photogrammetric survey acquisition

Each photo has a resolution of 4272x2848 pixel and about the focal length used it was $55 \mathrm{~mm}$ for the outdoor survey and $18 \mathrm{~mm}$ for the indoor environment. From each set of shots, it is obtained, through a photo stitching software, an equirectangular panorama with an average resolution of $10000 \times 8500$ pixel with a homogeneous exposure thanks to the adoption of automatic blending algorithms. (Fig. 4)
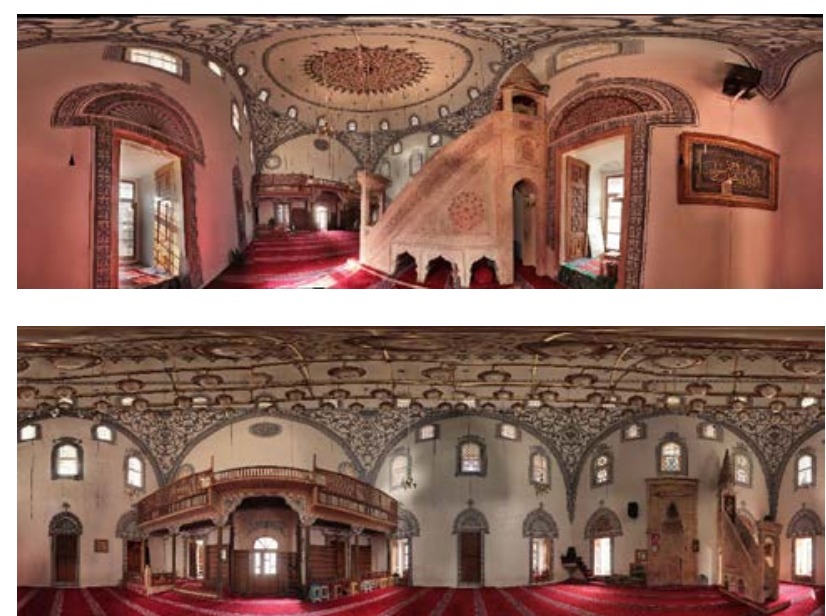

Figure 4. Examples of equirectangular panorama of indoor environment

After their orientation, using specific algorithms and complanarity processing (Fig. 5), the restitution by Spherical Photogrammetry (SP) method has given the wire-frame model processed in a 3D solid model by CAD projective geometry rules with a panoramic image-based interactive modelling. It exploits the geometrical constraints of the architecture's geometry to 
simplify the 3D modeling method. As just said, the photogrammetric reconstructions is based on SP: the advantages are the high resolution, the FOV up to $360^{\circ}$, the low cost, the completeness of the information and the high speed of takings photos. On the contrary, the plotting and the orientation are, up to now, fully manual. SP was mainly conceived and designed for cultural and architectural metric documentation. It was introduced by Fangi (2007, 2009) subsequent to the research carried out by Luhmann and Tecklenburg (2004) and by Schneider and Maas (2005). Since then it has been tested on several projects, performing the orientation of multiple panoramas and manual 3D object reconstruction. SP performs the bundle block adjustment (Fangi et al., 2013).

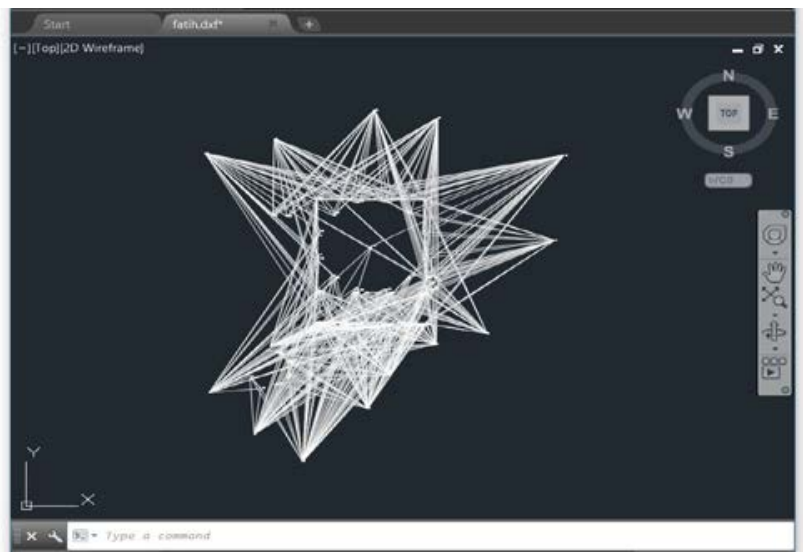

Figure 5. Orientation network of the spherical panoramas (outdoor)

To check the orientation network of the panoramas it needs to verify the linear errors in horizontal and zenital observations. Analysing the tables below (Fig. 6), you can find results of processing as output report from after the orientation. As you can see, the value of linear errors is correct, evaluating so the local georeferencing results reliable.

\begin{tabular}{|c|c|c|c|c|c|c|}
\hline \multicolumn{7}{|c|}{ OUTDOOR SURVEY } \\
\hline \multicolumn{7}{|c|}{ PLANIMETRY - Results of horizontal observations } \\
\hline n. & pnt. & pixel & gon. & correct. & distance & lin. residuals \\
\hline 8 & 28 & 93670 & 69,027 & $-0,3897$ & 35,618 & $-0,218 \mathrm{mt}$ \\
\hline \multicolumn{7}{|c|}{ ALTIMETRY - Results of zenital observations } \\
\hline n. & pnt. & pixel & gon. & correct. & distance & lin. residuals \\
\hline 658 & 22 & 1070 & 51,8804 & $-0,0078$ & 40,744 & $-0,3158 \mathrm{mt}$ \\
\hline
\end{tabular}

\begin{tabular}{|c|c|c|c|c|c|c|}
\hline \multicolumn{7}{|c|}{ INDOOR SURVEY } \\
\hline \multicolumn{7}{|c|}{ PLANIMETRY - Results of horizontal observations } \\
\hline n. & pnt. & pixel & gon. & correct. & distance & lin. residuals \\
\hline 105 & 36 & 137700 & 344,25 & $-0,9301$ & 9,368 & $-0,1369 \mathrm{mt}$ \\
\hline \multicolumn{7}{|c|}{ ALTIMETRY - Results of zenital observations } \\
\hline n. & pnt. & pixel & gon. & correct. & distance & lin. residuals \\
\hline 176 & 29 & 24080 & 60,2 & $-0,0099$ & 13,312 & $-0,1323 \mathrm{mt}$ \\
\hline
\end{tabular}

Figure 6. Residuals of linear errors after the orientation network

Afterwards, details were modelled on the main minaret body in correspondence with the image projections using the monoplotting. The solid 3D model can be drafted after an accurate operation of editing, representing a starting point for the BIM representation. (Fig. 7)

The final accuracy of the model is influenced by both the quality of the data surveyed and the modelling operations carried out, which are time consuming.

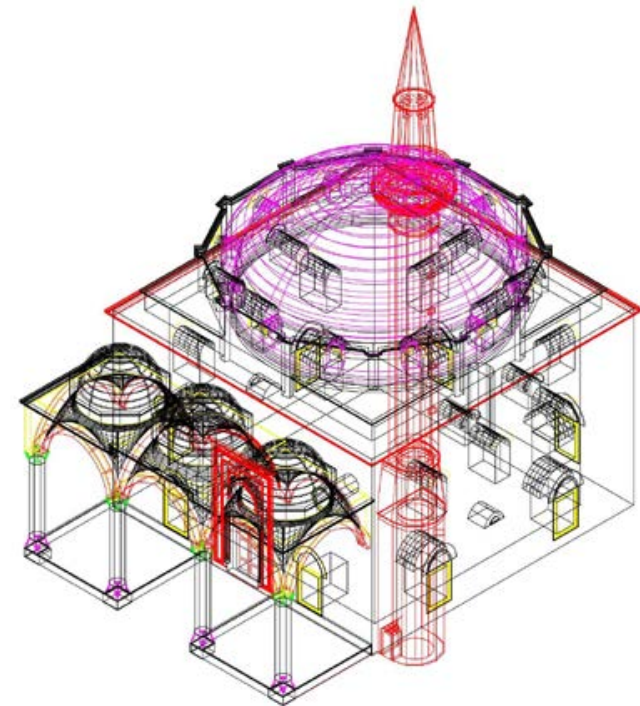

Figure 7. The edited 3d wire-frame

\subsection{HBIM implementation}

After this preliminary step, we decided to arrange the 3D model in Autodesk Revit (Fig. 8), suitable to implement a HBIM project. The model processing needs some considerations to decide how set up the data management and organization. It was vital to determine the levels of the modelled building. In the BIM structure, elements such as walls, windows, doors, stairs, must be tied to specific levels, modelled using families, i.e. ready-made elements. Therefore, irregular and deformed geometric shapes cannot be dealt with in standard way (Chevrier et al., 2010), so the easy solution is to create manipulating parametric surfaces. For these reasons we decided to adopt the parametric objectoriented modelling, basing on the use of pre-modelled object inserted in libraries of the HBIM software (Quattrini et al, 2015). Among software of direct modelling, we chose Rhinoceros to design 3D elements with complex shapes through operations of extrusion and revolution of composite profiles. These elements can be downloaded in the parametric model on software Autodesk Revit, used for the HBIM implementation.

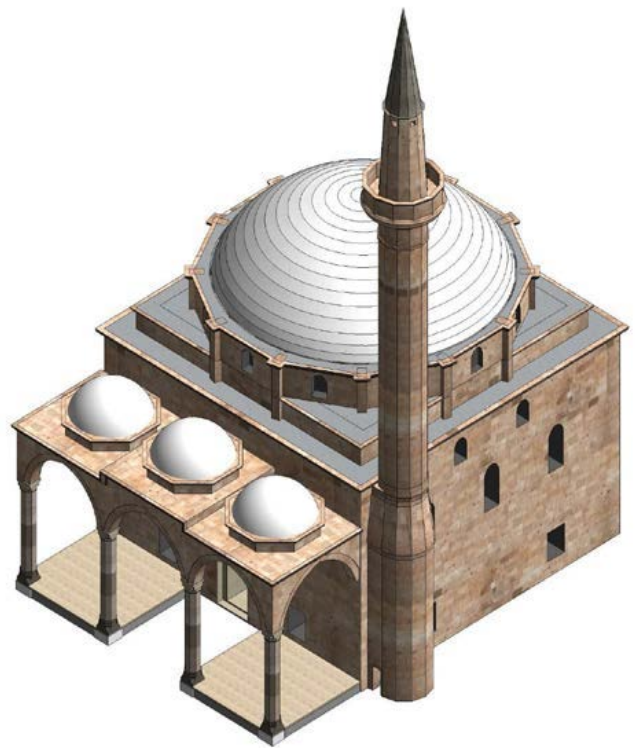

Figure 8. 3d model in Autodesk Revit 
Basing on the accuracy of the data acquisition, the availability of information about the building and the related level of knowledge, we have tried to operate a semantic segmentation of the complex structure based on different LoD (Level of Detail). In Revit software, it's not possible to define a specific LoD system so we connect the levels of detail to different scale of representation. Here we adopt this rule: high scale for more detailed object from 1:1 to 1:20, medium scale for the major architectural macro-elements in 1:50 or 1:100 and low scale for the whole complex representation from 1:200 upwards.

During the passage from CAD to Revit, obtained by the "explosion" of 3D model, it has occurred a simplification of the object creating different blocks ready to be imported in Revit and classified under its automatic schema category-family-type. Schema which is based the LoD assigned to each designed object. The result represents a new model with separated elements, easily to manage.

In the field of Cultural Heritage, in addition to the geometrical representation, it's important to consider and manipulate all this information, e.g. historical background, material composition, structural components, construction phases, decays, etc. So, to organize all this information and make useful for the conservation, valorisation and restoration interventions, one becomes crucial collect them in an "ad hoc" well-structured database possible to be linked to the 3D model.

So, thanks to BIM software, we can build a unique and flexible relational database, a sort of abacus of elements, appropriate to record and organize more features of each designed object. This kind of database works on the system entity-relationship: first identifying the entities in each record and then arrange the digital information defining the relations among different entities belonging to the same object. Moreover the relational database is characterized by a simple and good functionality, allowing a fast collection of information in input and for retrieving it, a multimedia data management and, in particular, the possibility to enrich it in any case, uploading new data. (Fig. 9)

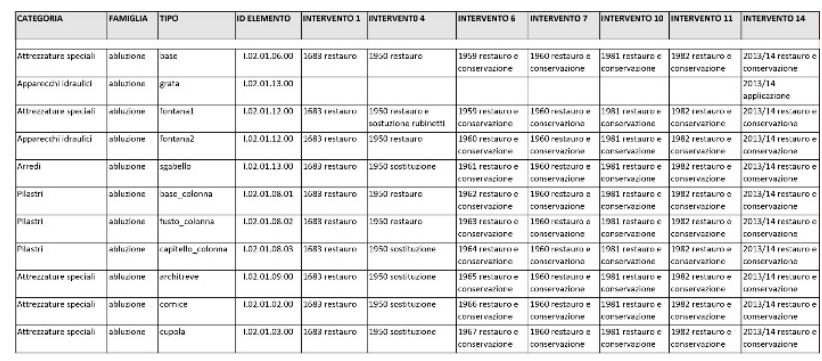

Figure 9. A section of the relational database

Non-geometrical attributes as textual information, historical images, types of material, decay analysis, interventions, etc. can be allocated in these specific libraries offered by Revit so can be linked to each feature component.

But notwithstanding Revit makes available customizable libraries to collect, for example, types of materials, and since the mosque represents an old building, not always can be found ready libraries from the software, so it is necessary to insert images or textures to identified them. Same reasoning is applied to the identification of different interventions during the history of the mosque and so the decay analysis. (Fig. 10)

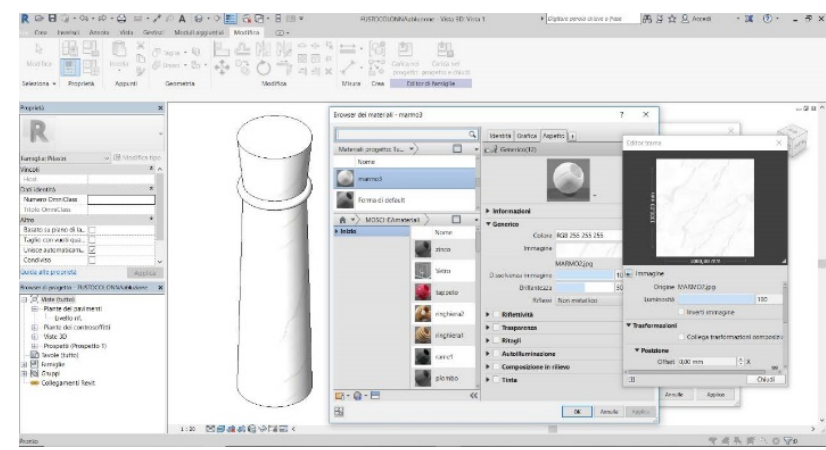

Figure 10. Customizable library collecting types of material

From a conceptual point of view, the mosque can be defined in different ways (functional, structural, stratigraphic, technological, etc.) and with different components (building, macro-areas, areas, technological systems, architectural elements, etc.), depending on the semantic classification and considering the graphical representation of each entity.

In this context five decreasing semantic LoDs were identified, described as follow: building in its complex (LoD 1), functional distribution of the building ( $\operatorname{LoD} 2$ ), the main islamic architectural elements which characterizing the funcional areas (LoD 3), the architectural sub elements which defining the volumetric architectural object (LoD 4), and specific detailed architectural elements such as decorations, components of columns, etc. (LoD 5) (Fig. 11).

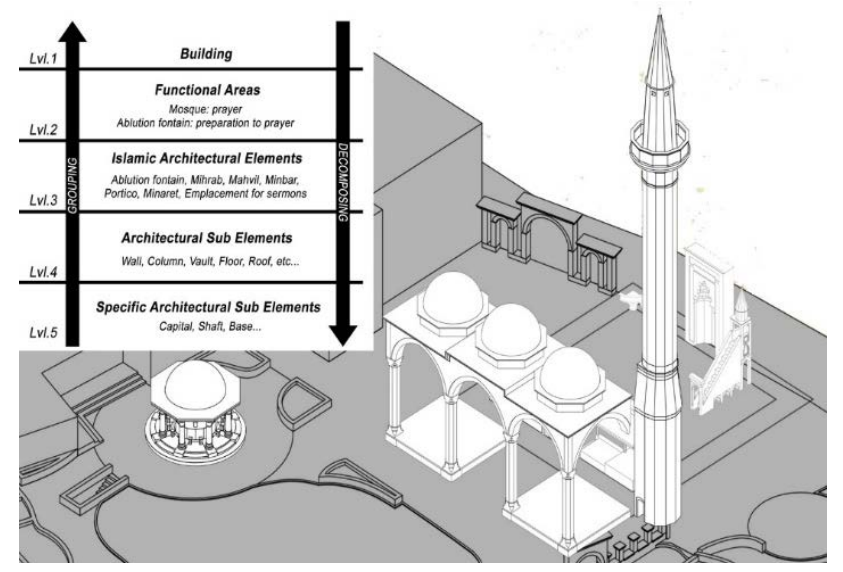

Figure 10. The semantic LoD classification and the example showing the LoD 3

Basing on a hierarchy of classes and subclasses, the implementation of a conceptual database organizes the building components assigning a not changeable ID numerical code easier to identify them by queries. The ID code is a combination of five numbers, each one representing the abovementioned $\mathrm{LoD}$. In this way each single object can be identified from the last number ( $\mathrm{LoD} 5$ ) to the first one (LoD 1) of the same combination to understand to which part of the building belong to (Fig. 11).

Then the classification system gives in output an ID code relating to any object, that contains information about the recognized object and also, if present, information about recognized subobjects.

This code can be then allocated in the relational database, linking to the related object and it can help to understand the relation and the link among the object composing the 3D model.

The main one is the possibility to flexibly mix BIM data and additional data created by operators via data enrichment, thus being able to perform cross-model queries. 
The next step consists in modelling the main information needs for the domain of interest, providing a data structure that can be leveraged to inform the data-enrichment phase and, later, to meaningfully query the data. The Ontology Web Language (OWL) can be used as ontology formalization language.

The resulting data contains all the information added can be queried via the standard Semantic-web query language (SPARQL). (Quattrini et al, 2017)

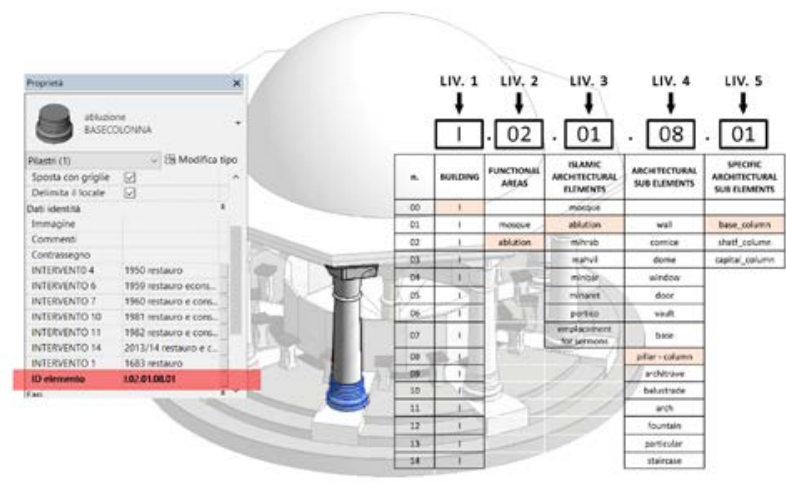

Figure 11. Example of ID code representing the base of the column of the ablution fountain

\section{DISCUSSION AND CONCLUSION}

The application carried out in this research shows that the use of HBIM in the Cultural Heritage field is a good solution and has big potentiality for an efficient management and preservation project. Nevertheless, a widespread application of HBIM system to cultural heritage buildings requires a large investment in terms of costs, training and processing times.

Because of the lower innovative progress and the difficulty to support a survey campaign by a poor country, as Kosovo is, the choice of using low-cost technology for the data acquisition is inevitable. How we explain in this research, the application of Spherical Photogrammetry represents a fast and appropriate technique for the following data processing.

The subdivision in small elements of the obtained 3D model has to be connected with the aim of the HBIM. This semantic segmentation that takes into account the structural, architectural and decorative elements seems to be very reasonable, as it is also suitable for three-dimensional analysis and not only 2D.

The definition of Level of Detail helps, in an in-depth analysis of the artefact, to make a meticulous geometric decomposing of the architectural components. A manageable method of semantic classification basing on allocating an ID-code for an easier search permits to find out quickly the required information using a query language system. Thanks to the HBIM software the ID-code assignment might be extended, not only to classify the architectural elements, but also to identify attributes like materials, interventions, etc.

Moreover, it represents the way all data will be accessed during the management of the architecture, so it helps the further steps of the HBIM process.

Our approach of work wants to represent an example of efficient information management and semantic classification can be repeated for the analysis and the documentation of another similar ottoman mosque. This database structure facilitates the finding of the searched information and permits to analyse and identify each architectural component in separated ways. Moreover, the use of HBIM has positive effects, in fact, as shown by literature, it simplifies the management of construction phases to keep track of the interventions, constituting a sort of unique and searchable archive. The other advantage is the concept of interoperability so different users can get involved and this allows the data sharing thanks to the usability typical of a HBIM software (Oreni et al., 2014).

In lack of a complete historical background, a HBIM model allows data enrichment and database updating at any time so it represents a starting point to upload with new data to the created database and generating links also to new typologies of data formats. This multimedia database is not suitable for the conservation or valorisation at the present time but it could preserve the memory of the historical building for the future generations and educational purposes.

The 3D model can also be exchanged and viewed through software and online platforms, even by those who have never used BIM software. This opens the way for the dissemination of HBIM with the creation of centralized models with multidisciplinary information that can be used in the field of conservation, but also for the valorisation of cultural heritage.

A future goal concerns the data migration from HBIM to the Semantic Web tool, in which users can browse the model filtering properties and viewing the $3 \mathrm{D}$.

In this framework, the present research answers to the following relevant topics: definition of the different categories of items from a photogrammetric survey and the CAD representation and their semantic organization in HBIM; connection between model and information considering each single item like a repository; management of items/repositories of information in libraries devoted to historical buildings, also to be implemented in the web environment through the OWL.

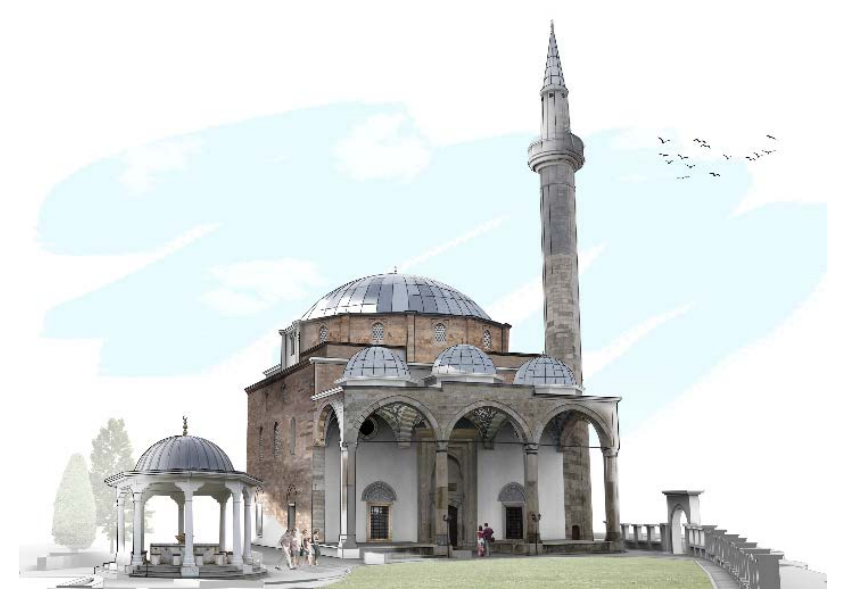

Figure 12. Final render of the mosque

\section{REFERENCES}

Akbarnezhad, A., Ong, K.C.G., Chandra, L.R., 2014: Economic and environmental assessment of deconstruction strategies using building information modeling, Autom. Constr., Vol. 37, pp. 131-144, https://doi.org/10.1016/j.autcon.2013.10.017

Antonopoulou, S., Bryan, P., 2017: BIM for Heritage: Developing a Historic Building Information; Historic England: Swindon, UK. 
Arayici, Y., 2008: Towards building information modelling for existing structures, Structural Survey, Vol. 26, pp. 210-222. DOI: $10.1108 / 02630800810887108$.

Barazzetti, L., Banfi, F., Brumana, R., Gusmeroli, G., Previtali, M., Schiantarelli, G., 2015: Cloud-to-BIM-to-FEM: Structural simulation with accurate historic BIM from laser scans, Simul. Model. Pract. Theory, Vol. 57, pp. 71-87.

Brumana, R., Della Torre, S., Oreni, D., Previtali, M., Cantini, L., Barazzetti, L., Franchi, A., and Banfi, F., 2017: HBIM Challenge Among The Paradigm Of Complexity, Tools And Preservation: The Basilica Di Collemaggio 8 Years After The Earthquake (L’Aquila), Int. Arch. Photogramm. Remote Sens., Vol. XLII-2, pp. 97-104, DOI: 10.5194/isprs-archives-XLII-2W5-97-2017

Bruno, N., Roncella, R., 2018: A restoration oriented HBIM system for cultural heritage documentation: the case study of Parma cathedral, Int. Arch. Photogramm. Remote Sens. Spatial Inf. Sci., Vol. XLII-2, pp 171-178, https://doi.org/10.5194/isprsarchives-XLII-2-171-2018, 2018

Bryde, D., Broquetas, M., Volm, J.M., 2013: The project benefits of building information modelling (BIM). Int. J. Proj. Manag., Vol. 31, pp. 971-980.

Chevrier, C., Charbonneau, N., Grussenmeyer, P., Perrin, J.P., 2010: Parametric documenting of built heritage: 3D virtual reconstruction of architectural details, Int. J. Archit. Comput., Vol. 8, pp. 135-150.

Coli, M., Ciuffreda, A. L., and Micheloni, M., 2019: An informative content 3D model for the hall holding the Resurrection of Christ by Piero della Francesca mural painting at Sansepolcro, Italy, Int. Arch. Photogramm. Remote Sens. Spatial Inf. Sci., Vol. XLII-2/W11, pp. 435-442, https://doi.org/10.5194/isprs-archives-XLII-2-W11-435-2019.

De Naeyer, A., Arroyo, S., Blanco, J., 2000: Krakow Charter 2000: Principles for Conservation and Restoration of Built Heritage; Bureau Krakow: Krakow, Poland.

Della Torre, S., Moioli, R., Pili, A., 2019: Digital tools supporting conservation and management of built cultural heritage. In. edited by Koenraad van Balen K., Aziliz Vandesande A. (eds) Innovative built heritage models and preventive conservation, pp. 101-106.

Department for Communities and Local Government of United Kingdom, 2012: Annex 2: Glossary, National Planning Policy Framework; Department for Communities and Local Government: London, UK.

Dore, C., Murphy, M., 2017: Current State of the Art Historic Building Information Modelling, Int. Arch. Photogramm. Remote Sens. Spatial Inf. Sci., Vol. XLII-2/W5, pp. 185-192, https://doi.org/10.5194/isprs-archives-XLII-2-W5-185-2017

Eppich, R., 2007: Recording, Documentation, and Management for the Conservation of Heritage Places; The Getty Conservation Institute: Los Angeles, CA, USA.

Fangi, G., 2007: The multi-image spherical panoramas as a tool for architectural survey. Int. Arch. Photogramm. Remote Sens. Spatial Inf. Sci., Vol. 36 (5/C53), pp. 311-316.
Fangi, G., 2009: Further developments of the spherical photogrammetry for cultural heritage. XXII International Committee for Cultural Heritage (CIPA).

Fangi, G., Nardinocchi, C., 2013: Photogrammetric Processing of Spherical Panoramas, The Photogrammetric Record, DOI: 10.1111/phor.12031

Gazzola, P., Leimare, R., Bassegoda-Nonell, J., Benavente, L., Daifuku, H, De Vrieze, P.L., Langberg, H., Matteucci, M., 1964: International Charter for the Conservation and Restoration of Monuments and Sites, International Council on Monuments and Sites (ICOMOS): Venice, Italy.

Gomes, L., Pereira Bellon, O. R., Silva, L., 2014; 3D reconstruction methods for digital preservation of cultural heritage: A survey, Pattern Recognition Letters, Vol. 50, pp. 314, doi: 10.1016/j.patrec.2014.03.023

Gómez-García-Bermejo, J., Zalama, E., Feliz, R., 2013: Automated registration of 3D scans using geometric features and normalized color data, Comput.-Aided Civ. Infrastruct. Eng., Vol. 28, pp. 98-111, DOI: 10.1111/j.1467-8667.2012.00785.x

Green, A., Dixon, J., 2016: Standing buildings and built heritage. Post Med. Archaeol., Vol. 50, pp. 121-133. https://doi.org/10.1080/00794236.2016.1169492

Hichri, N., Stefani, C., Luca, L.D.E., Veron, P. and Hamon, G., 2013: From point cloud to BIM: a survey of existing approaches. XXIV International CIPA Symposium, France, Proceedings of the XXIV International CIPA Symposium

Luhmann, T., Tecklenburg, W., 2004: 3D object reconstruction from multiple-station panorama imagery, Int. Arch. Photogramm. Remote Sens. Spatial Inf. Sci., Panorama Photogrammetry Workshop, Dresden, Germany

Macher, H., Landes, T. and Grussenmeyer, P., 2017: From Point Clouds to Building Information Models: 3D Semi-Automatic Reconstruction of Indoors of Existing Buildings, Applied Sciences, Vol. 7, DOI: 10.3390/app7101030

Malinverni, E. S., Mariano, F., Di Stefano, F., Petetta, L., Onori, F., 2019: Modelling in HBIM to document materials decay by a thematic mapping to manage the cultural heritage: the case of "Chiesa della Pietà" in Fermo, Int. Arch. Photogramm. Remote Sens. Spatial Inf. Sci., Vol. XLII-2/W11, pp. 777-784, https://doi.org/10.5194/isprs-archives-XLII-2-W11-777-2019, 2019.

Maxwell, I., 2016: COTAC BIM4C Integrating HBIM Framework Report; COTAC: London, UK.

Megahed, N., 2015: Towards a management. Theoretical framework for HBIM approach in historic preservation, Int. J.

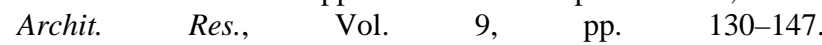
http://dx.doi.org/10.26687/archnet-ijar.v9i3.737

Ministry of Culture, Youth and Sport, 2016: National Strategy For Cultural Heritage 2017-2027, Republic of Kosovo

Murphy, M., McGovern, E., Pavia, S., 2009: Historic building information modelling (HBIM), Structural Survey, Vol. 27, pp. 311-327. DOI:10.1108/02630800910985108. 
Murphy, M., McGovern, E., Pavia, S., 2013: Historic Building Information Modelling - Adding intelligence to laser and image based surveys of European classical architecture, ISPRS Journal of Photogrammetry and Remote Sensing, Vol. 76, pp. 89-102. DOI:10.1016/j.isprsjprs.2012.11.006.

Oreni, D., Brumana, R., Della Torre, S., Banfi, F., Bertola, L., Barazzetti, L., Cuca, B., Previtali, M., Roncoroni, F., 2014: Survey turned into HBIM: the restoration and the work involved concerning the Basilica di Collemaggio after the earthquake (L'Aquila). Int. Arch. Photogramm. Remote Sens. Spatial Inf. Sci., Vol. II-5, ISPRS Technical Commission V Symposium, pp. 267-273.

Penttilä, H., Rajala, M., Freese, S., 2007: Building information modelling of modern historic buildings, In Proceedings of the 25th eCAADe Conference on Predicting the Future, pp. 607-613.

Petzet, M., 2004: Principles of preservation: An introduction to the International Charters for Conservation and Restoration 40 years after the Venice Charter. In: International Charters for Conservation and Restoration. Monuments and Sites, I. ICOMOS, pp. 7-29.

Quattrini, R., Malinverni, E.S., Clini, P., Nespeca, R., Orlietti, E., 2015: From TLS to HBIM. High quality semantically-aware 3D modeling of complex architecture, In Proceedings of 6th International Workshop 3DARCH "3D Virtual Reconstruction and Visualization of Complex Architectures”, Int. Arch. Photogramm. Remote Sens. Spatial Inf. Sci., Vol. XL-5/W4, pp. 367-374, https://doi.org/10.5194/isprsarchives-XL-5-W4-3672015, 2015

Quattrini, R., Pierdicca, R., Morbidoni, C., Malinverni, E. S., 2017: Conservation-oriented HBIM. The BIMexplorer web tool. Int. Arch. Photogramm. Remote Sens. Spatial Inf. Sci., Vol. XLII5/W1, pp. 275-281. https://doi.org/10.5194/isprs-archives-XLII5-W1-275-2017, 2017

Ramadan, S., 2007: Xhamia “Sulltan Mehmedfatih" (Xhamia e Madhe) (1460-61) në Prishtinëvepër madhëshshtore e trashëgimisë islame në Ballkan, Edukata Islame, Revistë shkencore, kulturore islame tremujore, Vol. XXXVI nr. 82, pp. 171-186

Spanish Ministry of Education, Culture and Sports, 2004: Plan Nacional de Abadías, Conventos y Monasterios [National Plan For Abbeys, Convents and Monasteries]; Spanish Government in collaboration with the Sacred Catholic Church

Virmiça, R., 1999: Faith Sulltan Mehemed Han Camii. (Camii Kebir) 865/1460-1461), Kosova'da Osmanli mimarieri, pp. 210215

Volk, R., Stengel, J., Schultmann, F., 2014: Building Information Models (BIM) for existing buildings - literature review and future needs, Automation in Construction, Vol. 38, pp.109-127. DOI: 10.1016/j.autcon.2013.10.023. 